\title{
PENGARUH PERSONAL SELLING TERHADAP KEPUTUSAN BERKUNJUNG DI JENDELA ALAM
}

\author{
Adhitya Aji Prasetyo \\ Oce Ridwanudin
}

\begin{abstract}
One of the areas in Indonesia which has many tourism potentials is West Java. It has so attracted many tourists for its beauty in natural and cultural resources. Bandung is the capital of West Java. It has so many tourists' attractions. One of the tourist's attractions is "Jendela Alam," the educational tourism destination that combines the idea of farm tourism activities and recreation park. Most of the visitors are students or schools that want to study about farming activities. However, there are many competitors that offered the same products and services right now, so the management has a big effort to anticipate the competitive situation. One of the efforts is by developing the personal selling activities to encourage schools for visiting the place. Thus, this research studied the personal selling as the independent variable that consists of some sub variables, namely, building relationship, closing the deal, and building loyalty. Furthermore, the dependent variable is the visiting decision. The method of the research is descriptive and verification research. The research instrument is the questionnaires that are distributed to 100 respondents. The data were analysed multiple regressions statistical analysis. The result shows that there was a significant influence between the personal selling activities of the visit decision to this tourists' attraction.
\end{abstract}

Keywords: personal selling, visiting decision, Jendela Alam

\section{PENDAHULUAN}

\subsection{Latar Belakang Penelitian}

Indonesia merupakan salah satu negara dengan keanekaragam potensi pariwisata yang melimpah, mulai dari potensi wisata alam hingga budaya dan Indonesia juga merupakan negara kepulauan, akan sangat mudah mengunjungi wilayah pesisir maupun pegunungan, letak geografisnya yang berada di khatulistiwa membuat Indonesia memiliki dua musim yaitu musim panas dan penghujan yang ideal untuk dikunjungi setiap tahun.

Dari sekian banyak wilayah yang tersebar, salah satu yang menjadi sasaran utama para wisatawan yaitu Provinsi Jawa Barat. Provinsi Jawa Barat merupakan salah satu provinsi yang memiliki banyak potensi wisata di dalamnya dan didukung oleh kekayaan alam dan budaya yang dimiliki menjadi salah satu daya tarik wisatawan untuk mengunjungi Jawa Barat. Jawa Barat memiliki banyak kabupaten didalamnya yang tentunya memiliki potensi wisata yang beragam dan salah satu yang berpotensi di Jawa Barat yaitu Kabupaten Bandung.

Banyaknya potensi wisata alam ini membuat para pengelola wisata berlomba-lomba mengembangkan potensi yang ada untuk menjadi sebuah destinasi wisata yang layak dikunjungi oleh para wisatawan. Pada saat ini pun bentuk atraksi wisata sudah semakin bervariasi dan dikemas dengan cara-cara yang unik salah satunya yaitu wisata edukasi dan salah satu wisata edukasi yang ada yaitu Jendela Alam.

Jendela Alam menjadi salah satu destinasi untuk melakukan kegiatan outing bagi rombongan sekolah. Hal ini tampak pada kunjungan wisatawan sebagai berikut :

TABEL 1

JUMLAH KUNJUNGAN WISATAWAN KE JENDELA ALAM TAHUN 2012-2014

\begin{tabular}{|c|c|c|}
\hline TAHUN & $\begin{array}{c}\text { JUMLAH } \\
\text { KUNJUNGAN } \\
\text { GROUP }\end{array}$ & $\begin{array}{c}\text { TARGET } \\
\text { KUNJUNGAN }\end{array}$ \\
\hline 2012 & 194 & 400 \\
\hline 2013 & 180 & 500 \\
\hline 2014 & 323 & 600 \\
\hline
\end{tabular}

Sumber: Marketing Jendela Alam 2015

Tabel menunjukan bahwa jumlah kunjungan wisatawan ke Jendela Alam dari tahun 2012 hingga 2014 terus mengalami peningkatan.

Tingkat kunjungan yang meningkat signifikan ternyata bukan pencapaian yang berarti dikarenakan jumlah kunjungan yang diperoleh belum mencapai target yang ditetapkan dikarenakan pihak sekolah atau instansi perusahaan yang lebih tertarik untuk melakukan kegiatan outing ke tempat wisata yang sudah dikenal.

Dalam upaya meningkatkan tingkat kunjungan, Jendela Alam memiliki beberapa strategi salah satunya program personal selling yang dijalankan Jendela Alam. Svend Hollensen (2010:89) mengemukakan bahwa "Personal selling Person-to-person interaction between a buyer and a seller wherein the seller's purpose is to persuade the buyer to accept a point of view, to convince the buyer to take a course of action, or to develop a customer relationship". Personal Selling yaitu interaksi dua orang antara penjual dan pembeli dimana penjual mengajak dan meyakinkan sang pembeli untuk melakukan serangkaian tindakan pembelian dan juga mengembangkan sebuah 
hubungan dengan konsumen Berdasarkan latar belakang di atas, maka perlu dilakukan suatu penelitian mengenai "PENGARUH PERSONAL SELLING TERHADAP KEPUTUSAN BERKUNJUNG DI JENDELA ALAM".

\subsection{Rumusan Masalah}

Berdasarkan latar belakang di atas, maka dapat dirumuskan masalah penelitian sebagai berikut:

1. Bagaimana personal selling di Jendela Alam.

2. Bagaimana tingkat keputusan berkunjung wisnus yang berkunjung ke Jendela Alam

3. Bagaimana pengaruh personal selling terhadap keputusan berkunjung wisatawan di Jendela Alam.

\subsection{Tujuan Penelitian}

Berdasarkan rumusan masalah di atas, maka tujuan penelitian ini adalah untuk memperoleh hasil temuan mengenai:

1. Memperoleh temuan mengenai personal selling di Jendela Alam

2. Memperoleh temuan mengenai gambaran tentang tingkat keputusan berkunjung wisatawan ke Jendela Alam

3. Memperoleh temuan mengenai pengaruh personal selling terhadap keputusan berkunjung wisatawan ke Jendela Alam

\subsection{Kegunaan Penelitian}

Penelitian penelitian ini diharapkan dapat memberikan manfaat kegunaan teoritis maupun praktis:

\section{Kegunaan Teoritis}

Secara teoritis, hasil penelitian ini diharapkan dapat memperluas kajian ilmu pemasaran, khususnya di bidang pemasaran destinasi

\section{Kegunaan Praktis}

Kegunaan praktis dari penelitian ini diharapkan dapat memberi masukan kepada Jendela Alam strategi apa yang dapat dilakukan untuk meningkatkan tingkat kunjungan wisatawan agar tingkat kunjungan wisatawan ke Jendela Alam dapat meningkat.

\section{KAJIAN PUSTAKA}

\subsection{Konsep Personal Selling dalam Pemasaran Destinasi}

Svend Hollensen (2010:89) mengemukakan bahwa "Personal selling Person-to-person interaction between a buyer and a seller wherein the seller's purpose is to persuade the buyer to accept a point of view, to convince the buyer to take a course of action, or to develop a customer relationship". Personal Selling yaitu interaksi dua orang antara penjual dan pembeli dimana penjual mengajak dan meyakinkan sang pembeli untuk melakukan serangkaian tindakan pembelian dan juga mengembangkan sebuah hubungan dengan konsumen.

Adapun dimensi personal selling yang dipakai pada penelitian ini yaitu dari Svend Hollensen (2010:508) yaitu : 1) Building the relationship, 2) Closing the deal and building loyalty. Building the Relationship, pada tahap ini perusahaan melakukan presentasi tentang produk yang akan dipasarkan. Presentasi harus dilakukan dengan baik karena akan menciptakan kesan tersendiri bagi konsumen. Presentasi yang baik diharapkan dapat mengajak konsumen untuk membeli produk yang kita pasarkan. Pentingnya dalam pemecahan masalah juga menjadi dasar dalam menciptakan hubungan yang potensial dengan penjual.

Closing the deal and building loyalty, Salah satu kemampuan yang penting dalam penjualan yaitu mengatasi keberatan konsumen. Apabila dapat diatasi maka konsumen akan puas. Dalam closing ini juga memiliki arti mendapatkan order pertama setelah terjadinya closing hal yang dapat dilakukan yaitu follow-up, yaitu tindak lanjut setelah kegiatan pembelian terjadi, ini dimaksudkan agar hubungan perusahaan dengan konsumen tetap terjalin.

$$
\text { Svend Hollensen (2010:511) }
$$

mengungkapkan bahwa personal selling merupakan cara yang efektif untuk menjual produk. Menurut Koshnick dalam Backstorm (2008:3) mengemukakan bahwa Penjualan dapat diartikan sebagai proses membantu dan mengajak konsumen untuk membeli sebuah produk dan memberikan keuntungan pada penjual.

\subsection{Keputusan Berkunjung}

Kotler dan Keller (2012:170) mengemukakan bahwa, "Preferensi konsumen diantara beberapa merek untuk memilih dan menggunakan mana merek yang lebih bermanfaat".

Kotler \& Keller (2012:170) mengungkapkan bahwa dimensi keputusan berkunjung diantaranya

\section{Brand}

Konsumen akan menentukan merek mana yang akan dipilih dan digunakan Kotler \& Keller (2012:231) Brand adalah nama, tanda, symbol, desain maupun gabungan dari semuanya, yang mengidentifikasi sebuah produk atau servis dari sebuah produk jual dan membedakan mereka dengan kompetitor lainnya.

2. Dealer

Setelah memilih merek maka konsumen akan mencari tempat dimana ia dapat memperoleh produk tersebut

3. Quantity 
Banyaknya jumlah barang yang akan dibeli oleh konsumen tersebut

4. Timing

Waktu yang tepat untuk membeli barang tersebut

5. Payment Method

Cara pembayaran yang dapat dilakukan oleh konsumen apabila konsumen tersebut sudah memutuskan untuk melakukan pembelian.

\subsection{Paradigma Penelitian}

Untuk menjawab keseluruhan permasalahan seperti yang dijelaskan dalam rumusan masalah, maka paradigma penelitian digambarkan pada Gambar berikut:

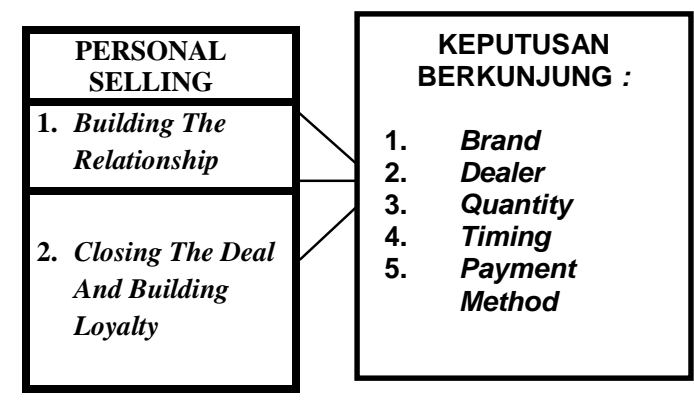

Gambar 1

Paradigma Penelitian

\subsection{Hipotesis}

Berdasarkan pemaparan ini, maka hipotesis penelitian dalam penelitian ini adalah sebagai berikut:

"Personal selling berpengaruh terhadap keputusan berkunjung baik secara simultan maupun parsial."

\section{METODE PENELITIAN}

\section{a. Objek Penelitian}

Penelitian dilakukan untuk menganalisis pengaruh personal selling terhadap keputusan berkunjung. Adapun yang menjadi objek penelitian sebagai variabel bebas (X) adalah personal selling yang terdiri dari Building the Relationship $\left(\mathrm{X}_{1}\right)$, dan Closing the Deal and Building Loyalty $\left(\mathrm{X}_{2}\right)$. Sedangkan keputusan berkunjung sebagai variabel terikat (Y) yang terdiri dari Brand $\left(\mathrm{Y}_{1}\right)$, Dealer $\left(\mathrm{Y}_{2}\right)$, Quantity $\left(\mathrm{Y}_{3}\right)$, Timing $\left(\mathrm{Y}_{4}\right)$, dan Payment Method $\left(\mathrm{Y}_{5}\right)$.

Unit analisis dalam penelitian ini adalah wisatawan group yang berkunjung ke Jendela Alam termasuk sekolah yang pernah mengunjungi Jendela Alam

\subsection{Metode Penelitian}

Berdasarkan variabel-variabel yang diteliti maka metode penelitian yang dipergunakan adalah metode penelitian deskriptif dan verifikatif.

\subsection{Metode Penarikan Sampel}

Ukuran sampel dihitung dengan menggunaan rumus Slovin (Husein Umar, 2009:78). Berdasarkan rumus tersebut, dengan derajat kesalahan sebesar 10\%, maka jumlah responden yang dijadikan ukuran sampel dalam penelitian ini ialah sebanyak 100 responden.

\subsection{Teknik Pengumpulan Data}

Teknik pengumpulan data yang digunakan oleh penulis adalah sebagai

berikut:

1.Kuesioner

2.Studi Literatur

3.wawancara

4.Observasi

\subsection{Pengujian Validitas dan Reliabilitas}

Selanjutnya, sebelum didistribusikan kepada responden, instrumen penelitian yang berupa kuesioner diuji terlebih dahulu. Uji yang dilakukan meliputi uji validitas dan reliabilitas. Hasil menunjukan bahwa instrumen penelitian valid dan reliabel.

\subsection{Pengujian Hipotesis}

Proses untuk menguji hipotesis dimana metode analisis yang dilakukan dalam penelitian ini adalah metode analisis verifikatif, maka dilakukan analisis regresi linear berganda.

Menurut Sugiyono (2014:275), regresi berganda digunakan oleh peneliti bermaksud meramalkan bagaimana keadaan (naik turunnya) variabel dependen (kriterium), bila dua atau lebih variabel independen sebagai faktor prediktor dimanipulasi (dinaik turunkan nilainya).

Analisis regresi berganda akan dilakukan bila jumlah variabel independen minimal dua atau lebih. Menerjemahkan ke dalam beberapa sub hipotesis yang menyatakan pengaruh sub variabel independen yang paling dominan terhadap variabel dependen, lebih jelasnya dapat dilihat pada seperti dapat dilihat pada gambar 3 berikut:

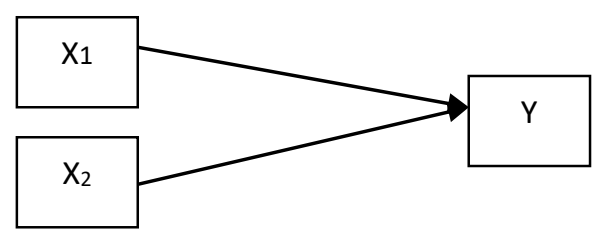

GAMBAR 2 REGRESI BERGANDA

Kriteria pengambilan keputusan hipotesis secara statistik dalam rangka pengambilan keputusan penerimaan atau penolakan hipotesis dapat ditulis sebagai berikut: 
1. Hipotesis nol $\mathrm{H}_{0}: \rho=0$ maka, tidak terdapat pengaruh signifikan antara personal selling terhadap keputusan berkunjung.

2. Hipotesis nol $\mathrm{H}_{0}: \rho \neq 0$ maka, terdapat pengaruh signifikan antara personal selling terhadap keputusan berkunjung.

Sub hipotesis 1

$H_{0}: \rho \leq 0$, artinya tidak terdapat pengaruh yang signifikan antara Building the Relationship terhadap keputusan berkunjung.

$H_{1}: \rho>0$, artinya terdapat pengaruh yang signifikan antara Building the Relationship terhadap keputusan berkunjung.

Sub hipotesis 2

$H_{0}: \rho \leq 0$, artinya tidak terdapat pengaruh yang signifikan antara Closing the Deal and Building Loyalty terhadap keputusan berkunjung.

$H_{1}: \rho>0$, artinya terdapat pengaruh yang signifikan antara Closing the Deal and Building Loyalty terhadap keputusan berkunjung.

\section{IV.HASIL PENELITIAN DAN PEMBAHASAN}

\subsection{Hasil Tanggapan Responden Terhadap Personal Selling di Jendela Alam}

Rekapitulasi mengenai hasil tanggapan wisatawan terhadap personal selling di Jendela Alam dapat dilihat pada Tabel 2 yang disajikan sebagai berikut

TABEL 2

REKAPITULASI HASIL TANGGAPAN RESPONDEN TERHADAP PERSONAL SELLING DI JENDELA ALAM

\begin{tabular}{|c|l|c|c|c|}
\hline No. & \multicolumn{1}{|c|}{$\begin{array}{c}\text { Sub } \\
\text { Variabel }\end{array}$} & $\begin{array}{c}\text { Total } \\
\text { Skor }\end{array}$ & $\begin{array}{c}\text { Skor } \\
\text { Rata- } \\
\text { rata }\end{array}$ & $\%$ \\
\hline 1. & $\begin{array}{l}\text { Building The } \\
\text { Relationship }\end{array}$ & 2143 & 357.16 & 50.16 \\
\hline 2. & $\begin{array}{l}\text { Closing The } \\
\text { Deal and } \\
\text { Building } \\
\text { Loyalty }\end{array}$ & 2484 & 453.85 & 49.84 \\
\hline Total & 4627 & 712.01 & 100 \\
\hline
\end{tabular}

Sumber: Hasil Pengolahan Data 2015
Berdasarkan Tabel 2 di atas dapat terlihat bahwa sub variabel dari personal selling Jendela Alam yang mendapatkan penilaian tertinggi yaitu pada Building the Relationship yaitu sebesar $50.16 \%$, hal ini menunjukkan bahwa salesperson Jendela Alam membangun dan memelihara hubungan baik dengan pihak-pihak sekolah mulai dari melakukan presentasi hingga komunikasi. Sedangkan sub variabel yang mendapatkan penilaian terendah adalah Closing The Deal and Building Loyalty dengan penilaian sebesar 49.84\%. Hal ini dikarenakan pihak dari Jendela Alam sendiri kurang optimal dalam hal membangun loyalitas kepada pihak sekolah.

\subsection{Hasil Tanggapan Wisatawan Terhadap Keputusan Berkunjung}

Rekapitulasi mengenai hasil tanggapan responden terhadap keputusan berkunjung dapat dilihat pada Tabel 3 yang disajikan berikut ini:

TABEL 3

\section{REKAPITULASI HASIL TANGGAPAN RESPONDEN TERHADAP KEPUTUSAN BERKUNJUNG}

\begin{tabular}{|c|l|c|c|c|}
\hline No. & $\begin{array}{c}\text { Sub } \\
\text { Variabel }\end{array}$ & $\begin{array}{c}\text { Total } \\
\text { Skor }\end{array}$ & $\begin{array}{c}\text { Skor } \\
\text { Rata- } \\
\text { rata }\end{array}$ & $\%$ \\
\hline 1. & Brand & 1415 & 353,75 & 20.69 \\
\hline 2. & Dealer & 699 & 349,5 & 20.44 \\
\hline 3. & Quantity & 1062 & 354 & 20.70 \\
\hline 4. & Timing & 595 & 297,5 & 17,40 \\
\hline 5. & $\begin{array}{l}\text { Payment } \\
\text { Method }\end{array}$ & 355 & 355 & 20,76 \\
\hline & Total & 4126 & 1709,75 & 100 \\
\hline
\end{tabular}

Sumber: Hasil Pengolahan Data 2015

Berdasarkan Tabel 3 di atas dapat terlihat bahwa sub variabel dari keputusan berkunjung yang mendapatkan penilaian tertinggi yaitu Payment Method dengan total skor 355, skor ratarata sebesar 355 dengan persentase $20,76 \%$. Wisatawan memberikan tanggapan yang baik terhadap sub variabel tersebut dikarenakan sebagian besar responden diberi kemudahan saat melakukan pembayaran dari Jendela Alam.

Penilaian terendah pada sub variabel timing yang mendapatkan nilai sebesar 595 dengan skor ratarata 297,5 dan persentase 17,40\%. Hal ini disebabkan karena biasanya sekolah datang pada hari biasa untuk melakukan outing dan jarangnya sekolah yang melakukan kegiatan outing di hari libur. 
4.3. Pengaruh Personal Selling Terhadap Keputusan Berkunjung

4.3.1 Pengujian Hipotesis dan Uji Signifikansi Secara Simultan (Uji F)

Uji F digunakan untuk mengetahui pengaruh keseluruhan variabel bebas terhadap variabel terikat. Uji $\mathrm{F}$ dapat dilakukan dengan membandingkan $F_{\text {hitung }}$ dengan $F_{\text {tabel }}$ untuk menguji signifikansi dari analisis regresi. Berikut output ANOVA seperti yang ditunjukkan pada Tabel 4 berikut :

TABEL 4 OUTPUT ANOVA

\begin{tabular}{|cl|c|c|c|c|c|}
\hline & Model & $\begin{array}{c}\text { Sum of } \\
\text { Squares }\end{array}$ & df & $\begin{array}{c}\text { Mean } \\
\text { Square }\end{array}$ & F & Sig. \\
\hline 1 & Regresion & 1765,652 & 2 & 882,826 & 28,818 &, $000^{\mathrm{a}}$ \\
& Residual & 2971,588 & 97 & 30,635 & & \\
& Total & 4737,240 & 99 & & & \\
\hline
\end{tabular}

Tabel 4 menunjukkan $F_{\text {hitung }}$ sebesar 28,818 , dengan nilai signifikansi yaitu 0,000 . Nilai signifikansi tersebut lebih kecil dari taraf signifikansi 0,05 atau 5\%, maka dapat dikatakan bahwa regresi dapat digunakan untuk memprediksikan pengaruh personal selling terhadap keputusan berkunjung. Cara lain untuk menguji $\mathrm{F}$ yatu dengan membandingkan nilai Fhitung dengan Ftabel. Dengan tingkat derajat kebebasan (DK) sebesar 0,05 atau 5\% untuk 100 responden maka didapat nilai $\mathrm{F}_{\text {tabelsebesar }} 2,14$ sedangkan untuk $F_{\text {hitung }}=28,818$. Dikarenakan $F_{\text {hitung }}>F_{\text {tabel }}$ yaitu sebesar 28,818> 2,14 dengan tingkat signifikansi 0,000 lebih kecil dari 0,5 dan hasil nya $F_{\text {hitung }}>F_{\text {tabel }}$ maka $\mathrm{H} 0$ ditolak dan $\mathrm{H} 1$ diterima yang artinya bahwa terdapat pengaruh yang signifikan dari personal selling terhadap keputusan berkunjung di Jendela Alam. Hasil pengujian hipotesis ini menyatakan bahwa terdapat pengaruh antara personal selling terhadap keputusan berkunjung.

\subsubsection{Pengujian Hipotesis dan Uji Signifikansi Secara Parsial (Uji t)}

Uji t berbeda dengan uji $F$, dimana uji $t$ digunakan untuk pengaruh masing-masing variabel bebas terhadap variabel terikat. Uji t ini dapat dilakukan dengan membandingkan thitung dengan $t_{\text {tabel. }}$. Berikut output koefisien regresi seperti yang ditunjukkan pada Tabel 5 berikut :
TABEL 5

KOEFISIEN REGRESI

\begin{tabular}{|l|c|r|c|c|c|}
\hline \multirow{2}{*}{ Model } & \multicolumn{2}{|c|}{$\begin{array}{c}\text { Unstandardized } \\
\text { Coefficients }\end{array}$} & $\begin{array}{c}\text { Standardized } \\
\text { Coefficients }\end{array}$ & t & Sig \\
\cline { 2 - 6 } & B & $\begin{array}{c}\text { Std. } \\
\text { Error }\end{array}$ & Beta & & \\
\hline (Constant) & 15.157 & 3533 & & 4,290 &, 000 \\
\cline { 2 - 6 } $\begin{array}{l}\text { X1 Building } \\
\text { The } \\
\text { Relationship } \\
\begin{array}{l}\text { X2 Closing } \\
\text { The Deal } \\
\text { and building } \\
\text { loyalty }\end{array}\end{array}$ &, 728 &, 728 &, 459 & 4,418 &, 000 \\
\cline { 2 - 6 } &, 390 &, 196 &, 207 & $, 1,991$ &, 049 \\
\hline
\end{tabular}

Berdasarkan Tabel 5 di atas menunjukkan bahwa pada taraf signifikansi 5\% sub variabel Building the Relationship dan Closing the Deal and Building Loyalty memiliki pengaruh secara signifikan bagi keputusan berkunjung. Sebagai penjelasan dari tabel di atas dalam membandingkan thitung dengan ttabel yaitu sebagai berikut:

1. Terdapat pengaruh yang signifikan antara dimensi Building the Relationship terhadap keputusan berkunjung dengan tingkat signifikansi $0,000<0,05$ dan $t_{\text {hitung }} 4,418$

$>$ 1,660 sehingga Ho ditolak dan H1 diterima

2. Terdapat pengaruh antara dimensi Closing the Deal and Building Loyalty terhadap keputusan berkunjung dengan tingkat signifikansi $0,049<0,05$

dan $t_{\text {hitung }} 1,991>1,660$ sehingga $\mathrm{HO}$ ditolak dan $\mathrm{H} 1$ diterima

Berdasarkan kedua dimensi di atas, 2 sub variabel yang ada yaitu Building the Relationship dan Closing the Deal and Building Loyalty memiliki pengaruh yang signifikan secara parsial terhadap keputusan berkunjung.

\subsection{Model Persamaan Regresi Berganda Pengaruh Personal Selling terhadap Keputusan Berkunjung \\ Persamaan regresi berganda untuk} pengaruh Personal Selling terhadap keputusan keputusan berkunjung Jendela Alam dapat dinyatakan sebagai berikut:

$\mathbf{Y}=\mathbf{a}+\mathbf{b}_{1} \mathbf{X}_{1}+\mathbf{b}_{2} \mathbf{X}_{2}$

$Y=15.157+0,728 X_{1}+0,390 X_{2}$

Keterangan:

$\mathrm{X}_{1=}$ Building the Relationship

$\mathrm{X}_{2}=$ Closing the Deal and Building Loyalty

$\mathrm{Y}=$ Keputusan berkunjung

Hasil analisis menunjukkan nilai konstanta sebesar 15,157 artinya bahwa jika setiap sub variabel X1,X2 personal selling bernilai 0 atau diabaikan maka tingkat keputusan berkunjung akan tetap bernilai 15,157 . Maka apabila nilai Building the Relationship dinaikan satu satuan maka keputusan berkunjung akan naik sebesar 
0,728. Apabila nilai Closing the deal and building loyalty dinaikan satu satuan maka keputusan berkunjung akan naik sebesar 0,390.

\subsection{Implikasi Hasil Temuan}

Temuan yang bersifat teoritik pada penelitian ini adalah bahwa berdasarkan hasil temuan penelitian, 2. Hasil penemuan penelitian, penulis memperkuat konsep personal selling terhadap keputusan berkunjung yang diungkapkan oleh Scott Mccabe (2009:242) "This is a highly effective form of communication because the seller can respond to the individual needs of the consumer and provide a tailored and flexible solution." Personal Selling merupakan bagian paling efektif dalam komunikasi karena penjual dapat memberi respon langsung kebutuhan konsumen secara individu dan memberikan sebuah solusi yang sesuai

Adapun temuan yang bersifat empirik antara lain sebagai berikut.

1. Temuan yang menunjukkan bahwa peran personal selling yang dilakukan oleh Jendela Alam penting untuk meningkatkan keputusan berkunjung. Berdasarkan pengujian yang telah dilakukan personal selling secara simultan memiliki pengaruh positif terhadap keputusan berkunjung.

2. Personal Selling yang meliputi Building the relationship dan closing the deal and building the loyalty memiliki pengaruh terhadap keputusan berkunjung dan untuk dimensi yang memiliki pengaruh paling kuat yaitu dimensi building the relationship, karena pada dimensi ini pihak Jendela Alam mempresentasikan langsung produk dan jasa yang dimilikinya kepada pihak sekolah, sehingga pihak sekolah dapat mengerti tentang detail dari produk dan jasa yang dipresentasikan. Sedangkan nilai yang lebih rendah terdapat pada dimensi closing the deal and building loyalty namun tetap dimensi ini juga memiliki pengaruh yang positif terhadap keputusan berkunjung.

\section{KESIMPULAN\& REKOMENDASI}

Berdasarkan Hasil penelitian yang dilakukan oleh peneliti melalui analisis deskriptif dan verfifikatif dengan menggunakan regresi linear berganda maka berdasarkan penelitian tersebut dapat diambil kesimpulan sebagai berikut:

1. Tanggapan responden mengenai pelaksanaan personal selling Jendela Alam terdiri dari dua sub variabel yaitu Building The Relationship dan Closing the deal and building loyalty. Sub variabel Building the Relationship memiliki penilaian yang paling tinggi dari responden. Penilaian ini didapatkan karena pihak Jendela Alam datang langsung mensosialisasikan ke tiap-tiap sekolah dan bertatap muka langsung dengan pihak sekolah.

2. Keputusan berkunjung memiliki beberapa sub variabel yang terdiri dari brand, dealer, quantity, timing, dan payment method. Sub variabel yang memiliki penilaian tertinggi yaitu pada sub variabel payment method, hal ini menunjukkan bahwa para responden merasa terbantu oleh sistem pembayaran yang dijalankan oleh Jendela Alam

3. Personal selling yang dilakukan Jendela Alam memiliki pengaruh yang signifikan terhadap keputusan berkunjung Jendela Alam. Adapun sub variabel dari personal selling yaitu Building The Relationship dan Closing the Deal and building loyalty berpengaruh terhadap keputusan berkunjung.

Berdasarkan hasil penelitian yang telah dilakukan, maka penulis merekomendasikan halhal sebagai berikut:

1. Personal selling yang dilakukan Jendela Alam sudah termasuk baik. Namun sebaiknya dilakukan beberapa perbaikan agar lebih optimal. Hasil penelitian menunjukkan sub variabel closing the deal and building loyalty memiliki nilai yang terendah. Oleh karena itu sebaiknya kegiatan follow up seperti menghubungi dan melakukan kontak kembali kepada pihak sekolah yang sudah berkunjung maupun belum berkunjung dan juga lebih ditingkatkan lagi dalam hal penanganan complain yang diajukan oleh pelanggan kepada pihak Jendela Alam.

2. Keputusan berkunjung ke Jendela Alam yang terdiri dari brand, dealer, quantity, timing, dan payment method, dalam hal ini sub variabel timing memiliki penilaian paling rendah karena sebagian besar pihak sekolah datang untuk berkunjung pada hari biasa atau hari kerja. Hal ini berkenaan dengan kesiapan dari kegiatan-kegiatan yang ada di Jendela Alam dimana pada hari biasa terdapat beberapa kegiatan yang tidak dapat dinikmati oleh pengunjung, dengan begitu pihak Jendela Alam harus membuat seperti jadwaljadwal tentang waktu operasi kegiatan.

3. Personal selling terdapat dua sub variabel diantaranya building the relationship dan closing the deal and building loyalty, dari kedua sub variabel tersebut yang memiliki pengaruh yang signifikan terhadap keputusan berkunjung, namun diantara kedua sub variabel tersebut yang memiliki penilaian rendah yaitu pada sub variabel closing the deal and building loyalty. Sub variabel tersebut berkaitan dengan membangun loyalitas kepada pelanggan, seperti penanganan komplain, penanganan 
kunjungan dari pihak sekolah, penanganan keberatan pelanggan dan follow up. Pihak sekolah merasa dalam penanganan yang dilakukan Jendela Alam sudah baik namun ada beberapa hal yang harus diperbaiki seperti dalam follow up dapat direspon dengan cepat dan juga memperbanyak tim dari Marketing sendiri agar pemasaran yang dilakukan dapat berjalan dengan maksimal.

4. Jendela Alam merupakan sebuah destinasi wisata edukasi yang masih berkembang, diharapkan dalam perkembangannya ini Jendela Alam dapat meningkatkan kualitasnya khususnya pelayanan dikarenakan Jendela Alam merupakan destinasi wisata yang tidak terlepas dari kegiatan jasa yang tentunya langsung dirasakan oleh para pelanggan.

5. Penelitian ini masih terdapat banyak kekurangan dan keterbatasan. Salah satunya dalam pengkajian teori personal selling dan keputusan berkunjung. Diharapkan agar penelitian selanjutnya dapat mengkaji lebih luas mengenai personal selling.

\section{DAFTAR PUSTAKA}

Backstrom, Lars. 2008. Personal Selling and Relationships

Husein Umar. 2009. Metode Penelitian untuk Skripsi dan Tesis Bisnis. Jakarta: Rajagrafindo Persada

Hollensen, Svend. 2010. Marketing Management a Relationship Approach. London. Prentice Hall. (e-book)

Kotler, Philip and Keller, Kevin Lanne. 2012. Marketing Management. $14^{\text {th }}$ Edition. Prentice Hall, Pearson

McCabe, Scott. 2009. Marketing Communications in Tourism and Hospitality: Concepts, Strategies and Cases. Oxford: Elsevier Ltd. (ebook)

Sugiyono. 2014. Metode Penelitian Kuantitatif Kualitatif dan R\&D. Bandung:Alfabeta . 2014. Metode Penelitian Bisnis, Bandung:

Alfabeta

Suharsimi, Arikunto. 2009. Prosedur Penelitian. Suatu Pendekatan Praktis. Yogyakarta : Bina Aksara

Ulber Silalahi. 2009. Metode Penelitian Sosial. Bandung: PT.Refika Aditama

Umar, Husein. 2009. Metode Riset Bisnis. Jakarta. PT Gramedia Pustaka.

Umar, Husein.2009. Riset Pemasaran dan Perilaku Konsumen. Jakarta: PT. Gramedia Pustaka Utama. 
